\title{
Financial Assessment of Ground Source Heat Pump Systems against Other Selected Heating and Cooling Systems for Australian Conditions
}

\section{G. Riyan Aditya Ian W. Johnston}

\author{
Olga Mikhaylova
}

\author{
Guillermo A. Narsilio
}

\begin{abstract}
Ground source heat pump (GSHP) systems can provide cost-effective space heating and cooling for buildings while using less fossil fuel compared to many conventional systems. Despite these benefits, they typically have higher upfront costs and longer payback periods than other heating and cooling systems. These costs are often seen as potential roadblocks for property owners to install GSHP systems over conventional systems. The financial attractiveness of GSHP systems can be increased by adopting a bybrid ground source heat pump (HGSHP) system where GSHP systems provide the baseload thermal energy with the balance provided by conventional systems. This paper assesses the lifetime costs of GSHP and HGSHP systems designed for seven major cities in Australia and compares these costs with the lifetime costs of conventional systems. The results indicate that adopting HGSHP systems in Australian climatic conditions (from tropical to cool temperate) and under current Australian installation and fuel costs can lower the normalised lifetime costs of heating and cooling compared to adopting a GSHP or a conventional system only for the same applications.
\end{abstract}

\section{INTRODUCTION}

In Australia, electricity is used for space heating and cooling of many buildings. The Australian Bureau of Statistics (2014) reported that for residential heating, 38\% of residents use electricity and 30\% use gas, while for cooling 49\% residents use an electrical air conditioner. Most of the electricity in the country is generated from coal and gas, which are traditionally low cost and reliable energy sources. However, burning these fuels to generate electricity leads to high greenhouse gas (GHG) emissions. Gas is also used directly in furnaces for heating which also contributes significantly to the overall GHG emissions.

To achieve long-term environmental sustainability, electricity and gas consumption needs to be reduced. Ground Source Heat Pump (GSHP) technology can contribute to this reduction because GSHP systems typically have higher coefficients of performance (CoP) compared to conventional heating and cooling systems. For example, GSHP systems have been reported to have a CoP between 3 to 5 (Bloom and Tinjum, 2016; Liu and Spitler, 2014; Lu et al., 2017; Michopoulos et al., 2007; Trillat-Berdal et al., 2006). Conventional heating and cooling systems, such as a reverse cycle air conditioners (RCAC, Air Source Heat Pump Systems), typically have a CoP of 2 to 4 (Huang, 2015; Liu and Spitler, 2014; Lu et al., 2017; Self et al., 2013; Wu, 2009). Other conventional systems which use electricity and gas to provide heating operate at a CoP of less than 1 and unable to provide cooling. Hence, GSHP systems are

G. Riyan Aditya (gregorius.aditya@unimelb.edu.au) is a PhD Candidate at the University of Melbourne, Olga Mikhaylova is a Geotechnical Engineer at Golder Associates Pty Ltd, Guillermo A. Narsilio is an Associate Professor at the University of Melbourne and Ian W. Johnston is a Professorial Fellow at the University of Melbourne 
typically deemed to provide cost-effective heating and cooling to buildings while using less fossil fuels than most conventional systems.

Despite their efficiencies, property owners find it difficult to adopt GSHP systems due to their higher upfront costs and longer payback periods (Karytsas and Choropanitis, 2017; Lu et al., 2017). One strategy to reduce these costs and payback periods is to utilise hybrid ground source heat pump (HGSHP) systems, whereby GSHPs provide the baseload thermal energy to buildings with the balance provided by other, usually conventional, systems during particularly hot and cold periods of the year. These systems take advantage of the relatively low installation costs of conventional systems and the relatively low operating costs of GSHP systems to make HGSHP systems attractive financially (Alavy et al., 2013; Mikhaylova et al., 2016; Nguyen et al., 2014). Several recent studies investigated the optimum sizing strategy for HGSHP systems by adjusting the shave factor of the systems. The shave factor is defined as the proportion of the total heating or cooling peak load provided by the GSHP (Alavy et al., 2013; Mikhaylova et al., 2016; Nguyen et al., 2014). The most optimum configurations of hybrid systems are the ones that result in the lowest net present values over the lifetime of the systems.

This study assesses the lifetime costs of GSHP and HGSHP systems for seven major cities in Australia (see Table 1) and compare them with lifetime costs of conventional systems. Each of these Australian cities has significantly different climatic conditions, and hence, energy needs. To compare HGSHP systems with other heating and cooling options, the hybrids are optimised using extensions of previously published optimisation methods discussed in Alavy et al. (2013) and Mikhaylova et al. (2016).

\section{DATA AND METHODOLOGY}

\section{Climatic conditions and thermal loads}

This study covers a wide range of climatic conditions, which vary from a tropical climate in the north to a cool temperate climate in the south. The hourly outside air temperature (OAT) data based on the typical meteorological year is retrieved for all the chosen cities from Meteonorm (2017). These hourly OATs are used to estimate the undisturbed ground temperature $(\mathrm{Tg})$ at shallow depths in each city. Tg is assumed as the average annual OAT plus $2^{\circ} \mathrm{C}$ as described in IGSHPA (2009). The heating and cooling loads in each city were calculated based on the bin method by IGSHPA (2009) with a balance point of $17.5^{\circ} \mathrm{C}$. This study assumes all buildings are residential with a peak load of $10 \mathrm{~kW}$. For simplicity, the effect of humidity in cooling operations is disregarded in this paper. Table 1 presents an overview of the input parameters and the peak heating and cooling load for each city.

Table 1. Locations, design temperatures and peak heating and cooling loads

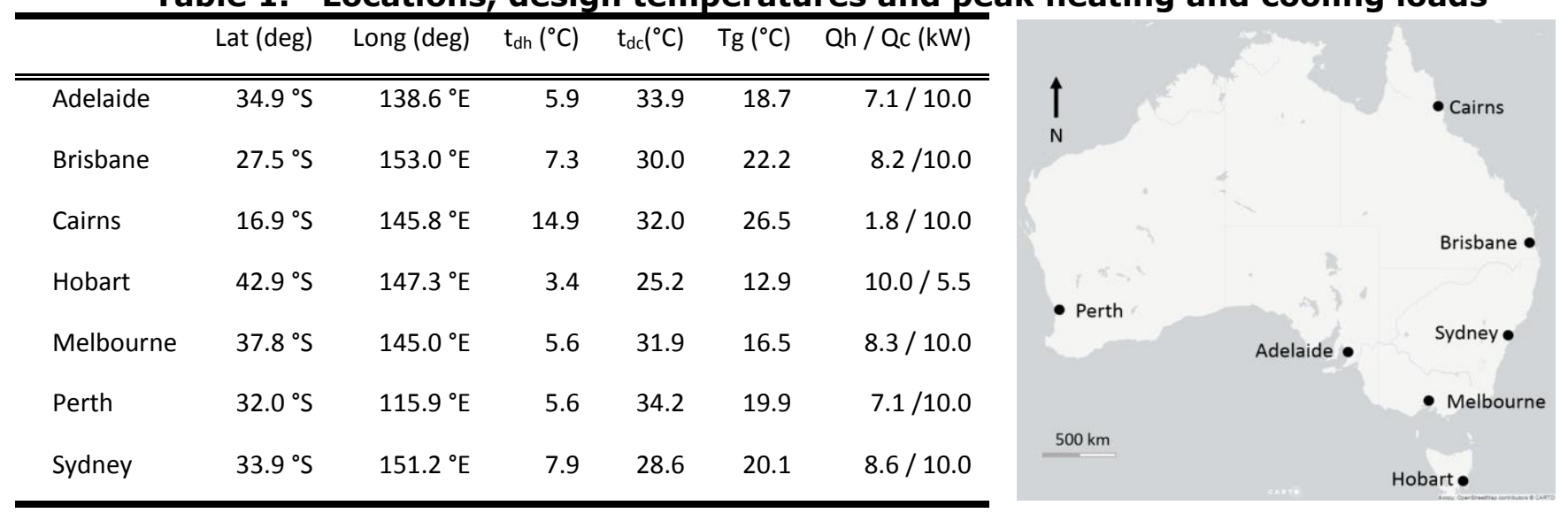

Notation: $t_{\mathrm{dh}}=$ heating design temperature, $\mathrm{t}_{\mathrm{dc}}=$ cooling design temperature, $\mathrm{Tg}=$ estimated ground temperature at shallow depth. Qh or Qc = estimated peak heating / cooling loads 


\section{Heating and cooling options}

The most common heating and cooling systems used in Australia are considered herein as conventional alternatives for GSHP systems. As such, the following options with their assumed CoPs are compared:

(1) Heating and cooling by an RCAC (CoP 2.5);

(2) Heating with a gas furnace (CoP 0.9) and cooling by an RCAC (CoP 2.5);

(3) Heating and cooling by GSHP (CoP 4);

(4) Heating and cooling by HGSHP system (HGSHP1) with a GSHP (CoP 4) and an RCAC (CoP 2.5); and

(5) Heating and cooling by HGSHP system (HGSHP2) with a GSHP (CoP 4), a gas furnace (CoP 0.9) for heating and an RCAC (CoP 2.5) for cooling.

This study considers only vertical ground heat exchangers (GHEs), where the required GHE length for the GSHP and HGSHP systems are calculated using the ASHRAE design approach shown in Equation 1 (Philippe et al., 2010).

$$
L_{G H E}=\frac{q_{h} R_{b}+q_{y} R_{10 y}+q_{m} R_{1 m}+q_{h} R_{6 h}}{T_{m}-\left(T_{g}+T_{p}\right)}
$$

Table 2 summarises most design parameters employed, including those used in Equation 1. To simplify the comparison between different locations, the same ground conditions (but not $\mathrm{T}_{\mathrm{g}}$ ) and GHE geometry are assumed in all sites.

\section{Financial Assessment}

Installation costs, inflation rates and discount rates for electricity and gas, and life spans of the systems are kept constant for all locations for simplicity. These parameters are based on the work by Lu et al. (2017) and are shown in Table 3. In particular, it has been assumed that the life spans of GSHP systems are 20 years. The life spans of both RCAC and gas boilers are assumed to be 10 years each. This means that both systems will need to be replaced once over the 20 years design life. It is assumed that the replacement costs of the RCAC and gas boilers are the same as their original prices because the yearly price increase of the equipment is aligned with the discount rate. Since a $10 \mathrm{~kW}$ system is relatively small, maintenance cost is not included in the analysis. All the financial analysis are conducted in Australian dollars (A\$), which at present is around US\$0.79.

The operating cost for the heating and cooling systems are calculated based on the current retail prices of electricity and gas in the cities studied. These prices are taken from the major energy retailers (Aurora Energy, 2017; Origin Energy, 2017; Synergy, 2017) and shown in Table 4 below. Whenever possible, the prices have been calculated based on the weighted price average during peak, off-peak and shoulder periods. It is important to note that the operating cost of the circulation pumps is assumed negligible for these small residential buildings.

Based on the above inputs, the Net Present Costs (NPC) were calculated for each of the heating and cooling option in the seven cities considered using Equation 2.

$$
N P C=\sum \frac{C_{t}}{(1+r)^{t}}
$$

where $C_{t}$ represents the cash outflow at time $t$ which can be a capital cost or an operating cost. This cost at time $t$ will be discounted back at interest rate $\mathrm{r}$ over the 20 year design life of the system. The NPC calculated here represents the present value of all outgoing cash flows during installation, operation, replacement (if necessary) over 20 years. 
Table 2. Parameters used for sizing of GHEs

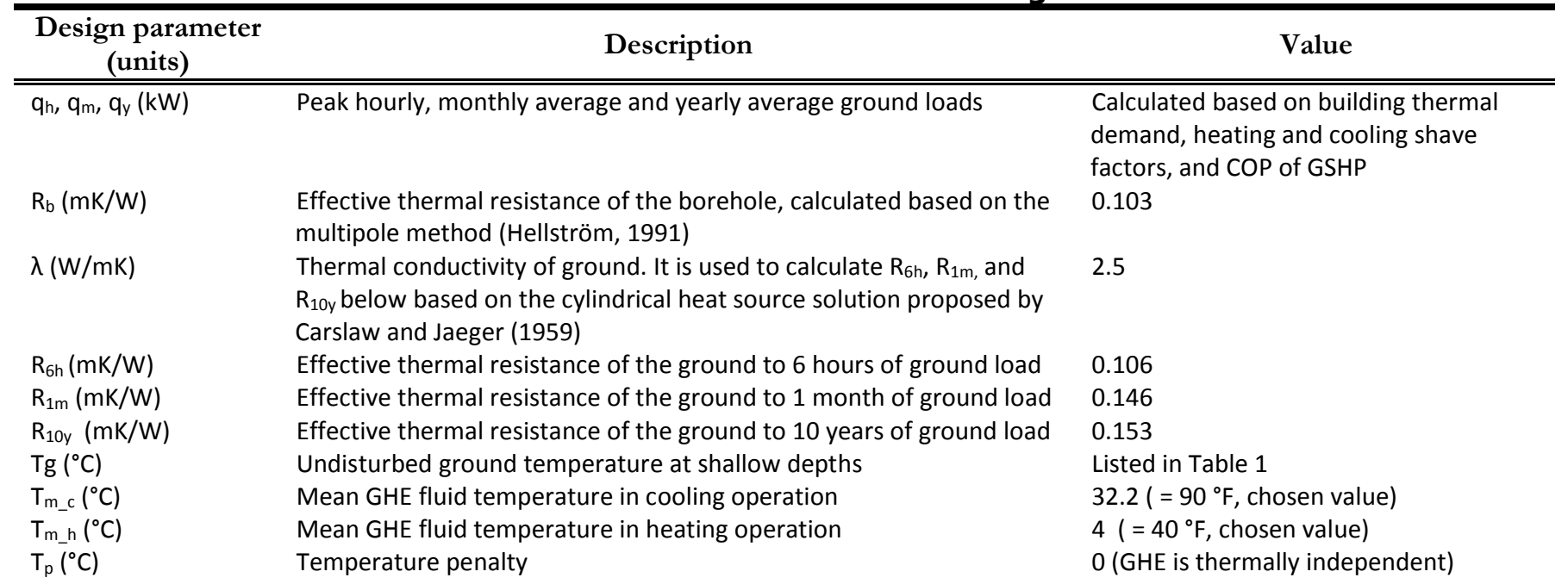

Table 3: Parameters used for financial assessment

\begin{tabular}{lll}
\hline \multicolumn{1}{c}{ Parameter (units) } & \multicolumn{1}{c}{ Value } & Note \\
\hline \hline Cost of drilling $(\mathrm{A} \$ / \mathrm{m})$ & 80 & Borehole installation \\
Cost of GSHP $(\mathrm{A} \$ / \mathrm{kW})$ & 2,000 & Equipment and installation of the system \\
Cost of RCAC (A\$/kW) & 1,000 & Equipment and installation of the system \\
Cost of gas boiler (A\$/kW) & 500 & Equipment and installation of the system \\
Electricity inflation rate (\%) & 6.2 & \\
Gas inflation rate $(\%)$ & 6.14 & \\
Discount rate, $\mathrm{r}(\%)$ & 3.5 & \\
Life span of GSHP system (years) & 20 & \\
Life span of RCAC and boiler (years) & 10 & \\
Replacement of RCAC and gas furnace & Every 10 years \\
Design life (years) & 20 & \\
\hline
\end{tabular}

Table 4: Electricity and gas price considered

\begin{tabular}{lrr}
\hline Cities & Electricity price $(\mathrm{c} / \mathbf{k W h})$ & Gas price $(\mathrm{c} / \mathbf{k W h})$ \\
\hline \hline Adelaide & 31.3 & 13.0 \\
Brisbane & 22.0 & 10.6 \\
Cairns & 22.0 & 10.6 \\
Hobart & 20.2 & 12.6 \\
Melbourne & 27.6 & 9.4 \\
Perth & 27.2 & 10.3 \\
Sydney & 23.8 & 12.6 \\
\hline
\end{tabular}

\section{RESULTS AND DISCUSSIONS}

\section{Annual thermal demands}

The calculated annual thermal demands for a $10 \mathrm{~kW}$ system run continuously in all the cities are shown in Figure 1. As expected, the annual thermal demand is highly correlated with the climatic conditions in each city presented in Table 1. For example, the results indicate that Hobart and Melbourne are heating dominant while the rest of the cities are cooling dominant. Perth is the city which has the most balanced heating and cooling thermal demands amongst all the cities considered. Since the demand for heating in Cairns is minor, less than $0.2 \mathrm{MWh}$, this study assumes that heating is not required in this city. 


\section{Net operating costs of GSHP and conventional systems}

The computed NPCs for GSHP and conventional systems are shown in Figure 2. The NPCs are broken down into the components associated with mechanical plant costs, GHE installation costs, and operating costs. Since heating is not needed in Cairns, only one conventional system (RCAC) is considered in this city.

The capital cost component of GSHP systems (plant and GHE costs) are always higher than conventional systems due to the GHE cost components of the system. The GHE length in each city is determined by the unique thermal load pattern as well as the undisturbed ground temperature. The calculated GHE length varies from $200 \mathrm{~m}$ in Melbourne to $600 \mathrm{~m}$ in Cairns as shown in Figure 2 below. In Cairns, additional GHE length is required to allow heat dispersion to the ground without compromising a GSHP system's efficiency in this highly cooling dominant climate.

Figure 2 also shows that the operating costs of GSHP systems are always lower compared to conventional systems in the same location. From the same figure, operating cost components represent the largest shares of the NPCs of most systems in all locations even after accounting for the high GHE installation costs.

In all locations except in Cairns, the GSHP systems are the cheapest heating and cooling options compared to the conventional systems. The distinct results for Cairns are due to the high GHE lengths needed as discussed above. This means that the financial benefits generated from the lower operating cost from using GSHP systems over 20 years design life are not enough to offset the high GHE installation cost in this city.

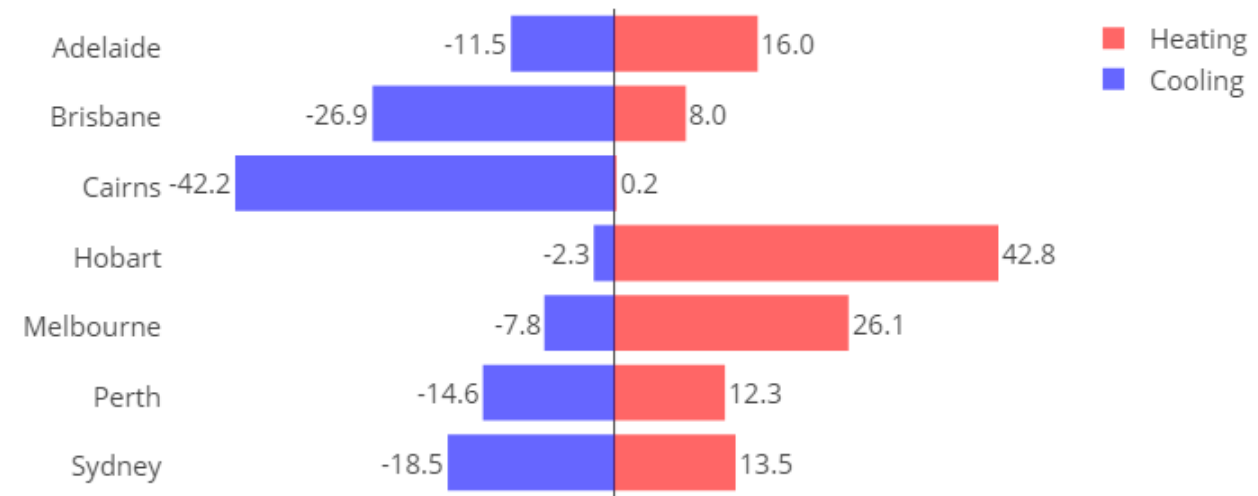

Figure 1 Annual heating and cooling demands in MWh of a typical $10 \mathrm{~kW}$ system. Negative values indicate cooling

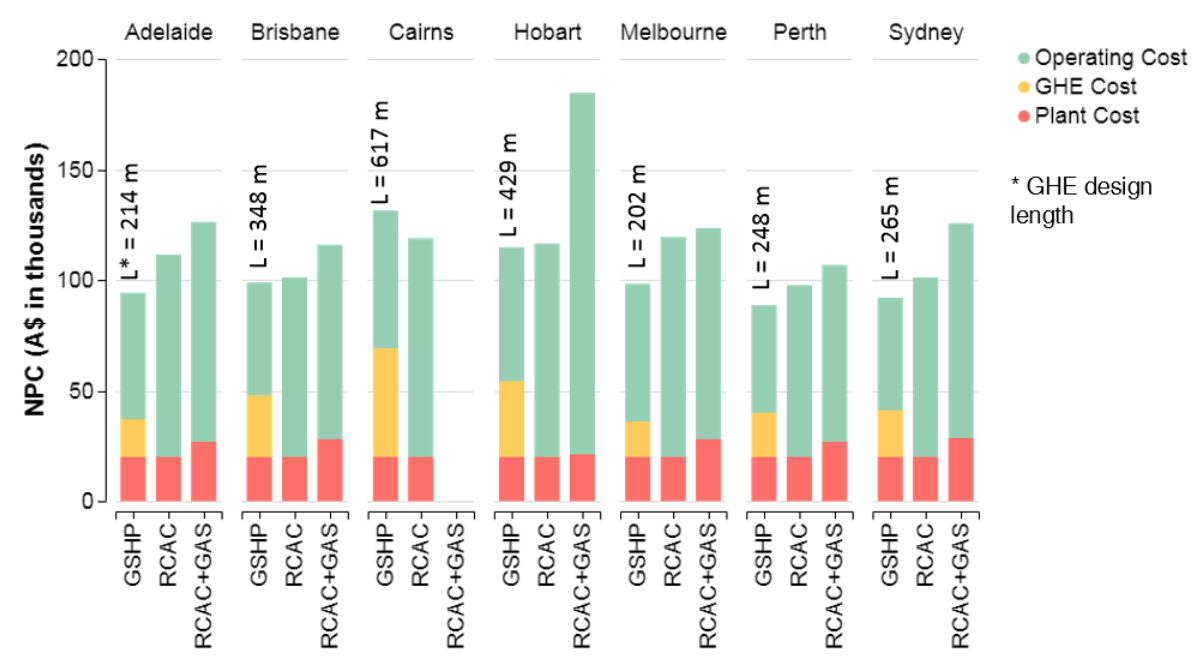

Figure 2 NPC in A\$ for GSHP and conventional systems 


\section{Hybrid ground source heat pump systems}

The previous section has demonstrated that GSHP systems generally have lower NPCs compared to conventional systems. However, their high upfront capital costs can make GSHP systems a less desirable heating and cooling option in Australia. The financial attractiveness of GSHP systems can be increased by adopting hybrid ground source heat pump (HGSHP) systems. In such systems, GSHPs provide the baseload thermal energy to buildings which are topped up by conventional systems during the hotter and colder days of the year. An example of this is shown in Figure 3 below where if a GSHP system in Sydney is sized to provide 50\% of peak heating and cooling load (a $50 \%$ shave factor giving $4.3 \mathrm{~kW}$ and $5.0 \mathrm{~kW}$ peak load), the GSHP systems can meet around $83 \%$ of the annual thermal energy requirements. Note that contrary to the northern hemisphere, winter in Australia occurs in mid-year.

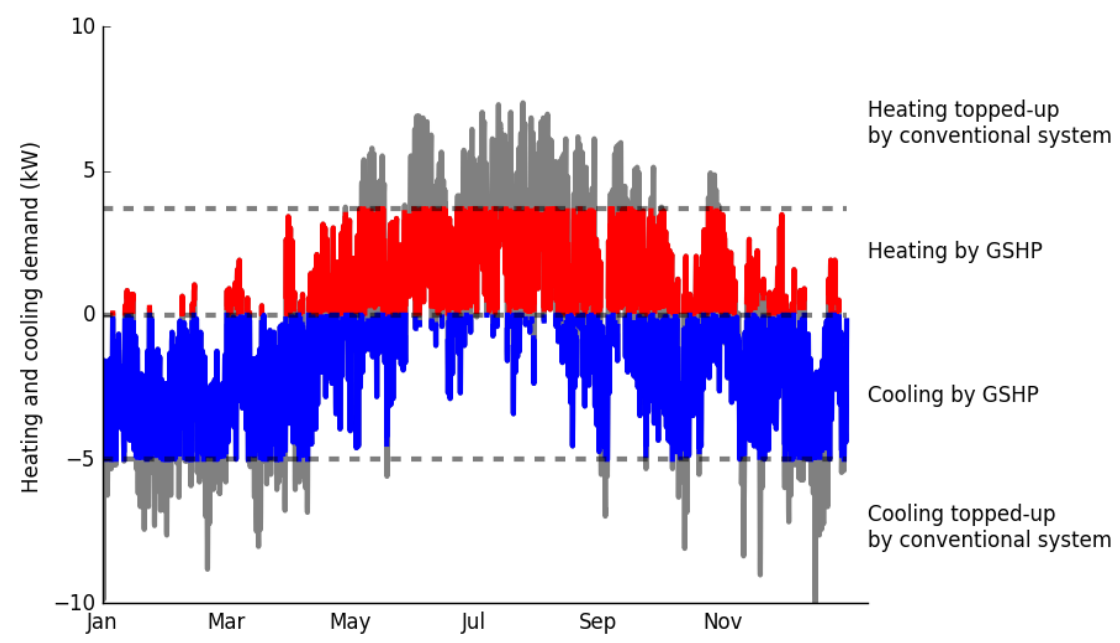

Figure 3 An example of a HGSHP in Sydney sized to meet 50\% of peak heating and cooling power demands

This section explores financial benefits of HGSHP systems that are sized to achieve minimum NPC of these systems over 20 years life span. The optimisation of the HGSHP systems performed using the method described in Mikhaylova et al. (2016). The NPC is further normalised by the total amount of thermal energy provided to the buildings over 20 years to allow comparisons between the cities, which is expressed as the Total Normalised Cost (TNC) in A $\$ / M W h$.

$$
T N C=\frac{N P C}{\text { Total thermal energy provided by the system }}
$$

Two HGSHP systems are considered here, where HGSHP1 is a combination of GSHP and RCAC systems, while HGSHP2 is a combination of GSHP, RCAC, and gas furnace systems. For each HGSHP system, the TNC is calculated for heating and cooling shave factors from $0 \%$ to $100 \%$ with a step size of $2 \%$. In these calculations, it is assumed that all input parameters are the same as stated in Table 2 to Table 4 and no additional costs arising from the complexity of installing hybrid systems over conventional systems since these costs could be minor for residential installations. This assumption may need to be revised for larger, more complex control of commercial systems.

As an example, Figure 4 presents the TNCs for HGSHP1 and HGSHP2 in Sydney. The bottom left corner of the plots represents $0 \%$ shave factor or, effectively, a conventional system. The top right corner of the plots represents a 100\% shave factor or, effectively, a GSHP system. The points in between represent the calculated TNC 
for different shave factor combinations of the HGSHP systems, where the TNCs are represented by contour lines. The lowest TNC is identified in the plot to indicate the most cost-effective shave factor combination for a HGSHP system where the system costs the least for a given amount of thermal energy produced. As discussed earlier, Sydney has a relatively balanced climate with a similar amount of heating and cooling energy required for a typical residential building. For this reason, both shave factors considerably influence the TNCs.

From Figure 4, the lowest TNC for HGSHP1 in Sydney is A $\$ 136 /$ MWh where the GSHP system is designed to provide $62 \%$ and $54 \%$ of the peak heating and cooling power demands respectively (Figure $4 \mathrm{a}$ ). This enables the GSHP system to meet around $88 \%$ of the thermal demand. For the same city, the lowest TNC for HGSHP2 is A $\$ 140 / \mathrm{MWh}$, where the GSHP system is designed to provide $90 \%$ and $78 \%$ of the peak heating and cooling power demands respectively (Figure 4b). This enables the GSHP system to meet around 98\% of the thermal demand. The plots in Figure 4 demonstrates that it is important to optimise HGSHP system sizing to maximise return on investment.
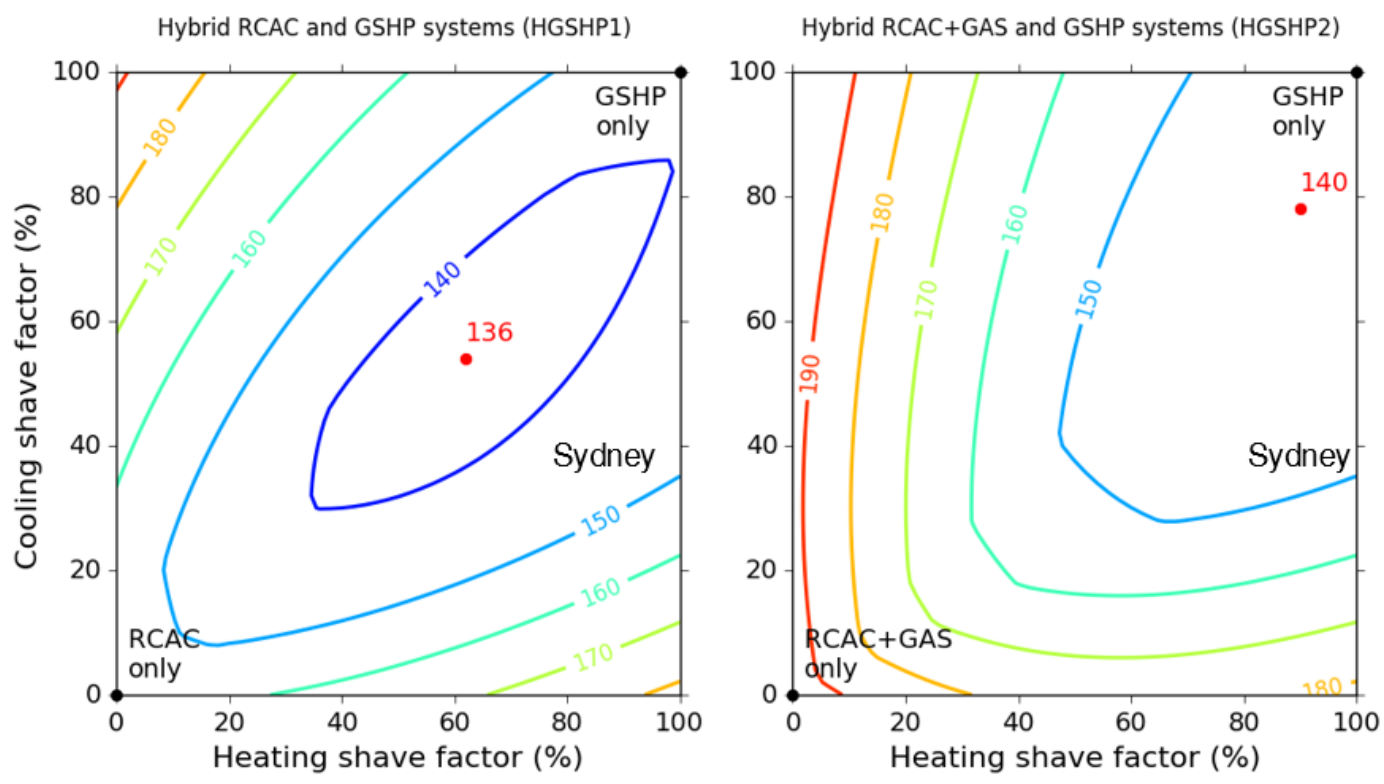

Figure 4 TNC values in $\mathbf{A} \mathbf{\text { MWh }}$ of HGSHP1 (a) and HGSHP2 (b) systems for Sydney.

Figure 5 summarises the TNC calculations for all five heating and cooling options in the seven cities considered. For HGSHP systems, the TNCs values of optimised configurations (the lowest TNC) are shown. The figure also presents the TNC values normalised with respect to the TNC of GSHP systems in each city, shown as values above each column. A normalised TNC of 1 represents the TNC for GSHP systems in each city. If a normalised value of TNC is more than 1, the system's TNC is higher than the TNC of a GSHP system in the same city and vice versa.

The TNC for GSHP systems varies from $A \$ 127 / \mathrm{MWh}$ in Hobart to $\mathrm{A} \$ 171 / \mathrm{MWh}$ in Adelaide. This suggests that $1 \mathrm{MWh}$ of thermal energy supplied by a GSHP system over 20 years is the cheapest in Hobart and the most expensive in Adelaide. These results directly correlate with the unit costs of electricity in these cities (Table 4). Overall, the TNCs of GSHP systems are lower compared to conventional systems, in all cases except in Cairns.

For all locations, the TNC for both types of HGSHP systems are 1 to $10 \%$ lower than the TNCs of GSHP systems, which means that the hybrid systems are more financially beneficial than GSHP systems. However, the benefits may be relatively minor. Another observation is that the capital costs of hybrid systems are lower than the capital costs of GSHP systems, which is mainly due to the reduction in the required GHE length. This means that 
hybrid systems can be more attractive than GSHP systems due to lower required initial investments which can be the primary motivation to install HGSHP systems over GSHP systems for some home owners.

In comparison to conventional systems, HGSHP systems can reduce TNC by up to $40 \%$ as shown by the HGSHP2 system in Hobart. It is important to note that unlike the GSHP system, a HGSHP system in Cairns has a lower TNC than a conventional system, where the TNC for HGSHP1 in Cairns is A $\$ 138 / \mathrm{MWh}$ compared to $\mathrm{A} \$ 140 / \mathrm{MWh}$ for a conventional system. In this case, the hybrid system needs to be sized to meet $24 \%$ of the cooling peak load, assuming that the system does not require any heating in Cairns.

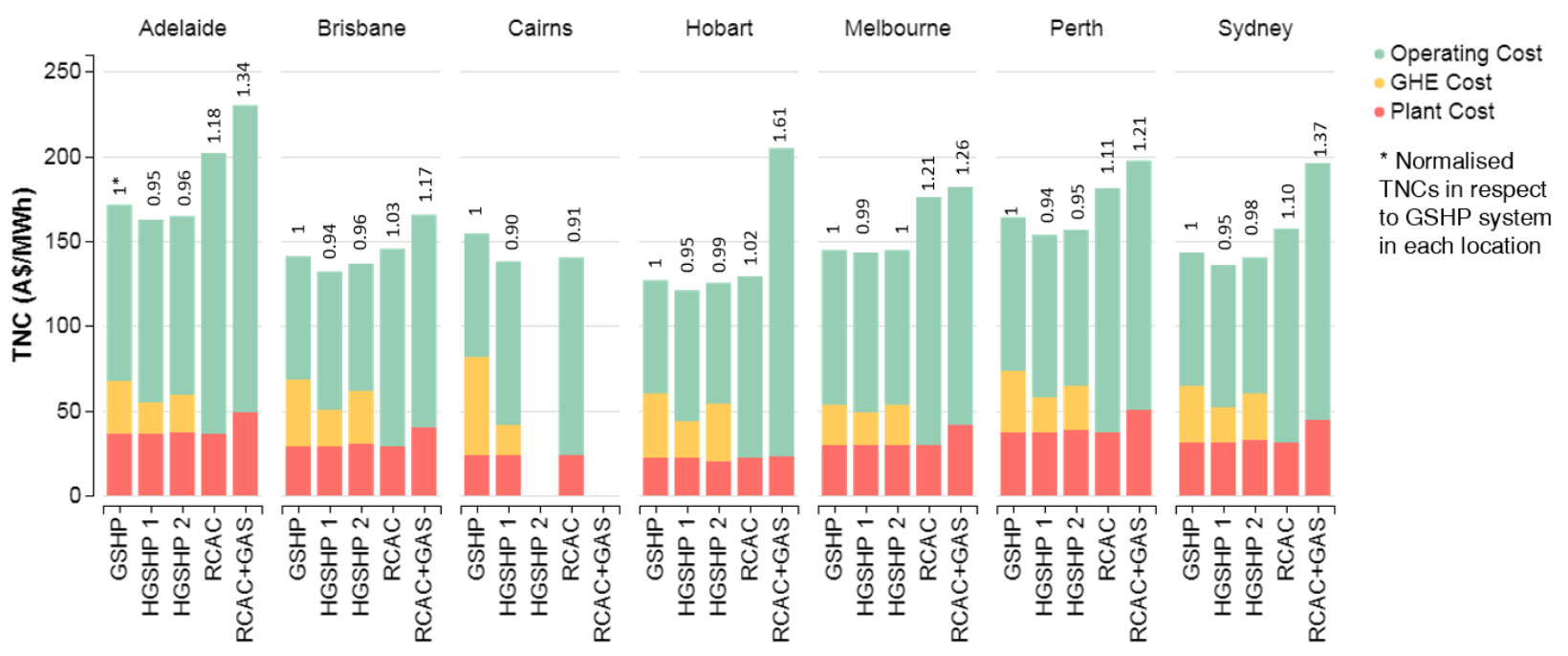

Figure 5 Lowest TNC in $\mathbf{A} \mathbf{\$} / \mathbf{M W h}$ comparisons between HGSHP1, HGSHP2, GSHP and conventional systems

\section{CONCLUSION}

This paper has shown that ground source heat pump (GSHP) systems can have lower net present costs compared to conventional systems even with the high installation costs of the systems in Australia. Although for the specific cases considered, hybrid systems were only marginally cheaper than GSHP systems, they appear to have the potential to further reduce lifetime costs, particularly in cooling dominated climates. However, further detailed and/or sensitivity analyses are necessary. In a hybrid ground source heat pump (HGSHP) model, the GSHP systems provide the baseload thermal energy to buildings, which is topped up by conventional systems during the hotter and colder days of the year.

HGSHP systems can be more attractive than GSHP systems due to lower required initial investments. However, HGSHP systems need to be sized to maximise the financial investment return. This can be a complicated process where designers need to consider the climatic conditions, as well as the energy prices in the locations where the system is being installed. Adopting a HGSHP system in Australia can reduce the total normalised cost over 20 years life span of the systems by up to $10 \%$ and $62 \%$ compared to an equivalent sized GSHP and conventional systems respectively depending on location. With the wide range of climatic conditions considered, the new insights developed may be transferable to other parts of the world with similar climatic conditions.

\section{ACKNOWLEDGMENTS}

The authors appreciate the support of the Australian Research Council, The Victorian Government and The University of Melbourne. 


\section{REFERENCES}

Alavy, M., Nguyen, H. V., Leong, W. H. \& Dworkin, S. B., 2013, A methodology and computerized approach for optimizing hybrid ground source heat pump system design, Renewable Energy 57:404-412.

Aurora Energy, 2017, Energy and Gas Prices, See https://www.auroraenergy.com.au/your-home (accessed July 2017).

Australian Bureau of Statistics, 2014, 602.0.55.001 - Environmental Issues: Energy Use and Conservation, Mar 2014.

Bloom, E. F. \& Tinjum, J. M., 2016, Fully Instrumented Life-Cycle Analyses for a Residential Geo-Exchange System, Geo-Chicago 2016, pp. 114-124.

Carslaw, H. S. \& Jaeger, J. C., 1959, Conduction of heat in solids, Oxford: Clarendon Press, 1959, 2 nd ed.

Hellström, G., 1991, Ground heat storage: thermal analyses of duct storage systems, Department of Mathematical Physics, Lund Univ.

Huang, S., 2015, Energy performance evaluation and optimisation of ground source heat pump systems, University of Wollongong.

IGSHPA, 2009, Ground Source Heat Pump Residential and Light Commercial Design and Installation Guide, Oklahoma State University, Stillwater, OK, USA.

Karytsas, S. \& Choropanitis, I., 2017, Barriers against and actions towards renewable energy technologies diffusion: A Principal Component Analysis for residential ground source heat pump (GSHP) systems, Renewable and Sustainable Energy Reviews 78:252-271.

Liu, X. \& Spitler, J., 2014, Performance of HVAC Systems at ASHRAE HQ, ASHRAE Journal 56(12):12.

Lu, Q., Narsilio, G. A., Aditya, G. R. \& Johnston, I. W., 2017, Economic analysis of vertical ground source heat pump systems in Melbourne, Energy 125:107-117.

Meteonorm, 2017, Typical Meteorological Year, See http://www.meteonorm.com/ (accessed June 2017).

Michopoulos, A., Bozis, D., Kikidis, P., Papakostas, K. \& Kyriakis, N., 2007, Three-years operation experience of a ground source heat pump system in Northern Greece, Energy and Buildings 39(3):328-334.

Mikhaylova, O., Choudhary, R., Soga, K. \& Johnston, I. W., 2016, Benefits and optimisation of district hybrid ground source heat pump systems. In Energy Geotechnics.) CRC Press, pp. 535-541.

Nguyen, H. V., Law, Y. L. E., Alavy, M., Walsh, P. R., Leong, W. H. \& Dworkin, S. B., 2014, An analysis of the factors affecting hybrid ground-source heat pump installation potential in North America, Applied Energy 125:28-38.

Origin Energy, 2017, Electricity and gas prices, See https://www.originenergy.com.au/for-home.html (accessed July 2017).

Philippe, M., Michel Bernier PhD, P. \& Marchio, D., 2010, Sizing calculation spreadsheet: Vertical geothermal borefields, ASHRAE Journal 52(7):20.

Self, S. J., Reddy, B. V. \& Rosen, M. A., 2013, Geothermal heat pump systems: Status review and comparison with other heating options, Applied Energy 101:341-348.

Synergy, 2017, Electricity and Gas Prices, See https://www.synergy.net.au/ (accessed July 2017).

Trillat-Berdal, V., Souyri, B. \& Fraisse, G., 2006, Experimental study of a ground-coupled heat pump combined with thermal solar collectors, Energy and Buildings 38(12):1477-1484.

Wu, R., 2009, Energy efficiency technologies-air source heat pump vs. ground source heat pump, Journal of Sustainable Development $2(2): 14$. 